\title{
Analysis of the dosage controversy in recess-resect and Faden surgery with the Robinson Computer Model of eye movements
}

\author{
HUIBERT J. SIMONSZ \& BOB VAN DIJK \\ Netherlands Ophthalmic Research Institute, P.O. Box 12141, 1100 AC Amsterdam, the \\ Netherlands
}

\begin{abstract}
In recess-resect surgery, the dosage depends on the preoperative angle of squint and on the ratio between squint-angle reduction and dosage that the surgeon has found in previous surgery. Recommendations pertaining to this ratio vary widely among authors. Some say a recession does more than a resection, while others believe the opposite is true. Finally, most find a lower ratio at smaller preoperative angles of squint. We investigated the matter, using our modified version of the Robinson computer model of eye movements. We calculated the amounts of surgery needed to reduce $10,15,20,25$ and 30 degree angles of squint to zero. The increase of the ratio at large angles of squint was indeed predicted by the model. The decrease at small angles of squint, however, was not predicted by the model. We found it impossible to model the decrease of the ratio at small preoperative angles of squint. The ratios for recess and resect surgery were approximately similar. We present an inventory of the possible causes of the discrepancies. In addition, we calculated the effects of Faden surgery and found that the predictions of the computer model correspond closely to reality.
\end{abstract}

\section{Introduction}

A controversy has stirred the strabismological community for over a century now, namely, how much surgery to do for different angles of squint. A1brecht von Graefe wrote a 210-page article on strabismus surgery in 1857 [1], in which he mentioned the dose-response relationship for the first time. He measured the distance between the nose and the two corneae with compasses, while the patient fixated an object in the median plane. The difference between the two served as a measure for the angle of squint. He aimed at recessing the muscle by this amount, for: 'Es wird der Bulbus ungefaehr um den Bogen, um welchen die Muskelsehne auf dem ihr zugehoerigen Scleralkreise zurueckgelagert ist, nach der Seite des Antagonisten hinueberfallen.' He did uni- or bilateral partial tenotomies, complete tenotomies and complete tenotomies with cuts in Tenons capsule, to tailor his surgery. He found that surgery for divergence is less effective than similar surgery for convergence. Von Pflugk [2] was the first to use a degree/ $\mathrm{mm}$ ratio (squint-angle reduction per millimeter of surgery), based on the notion that 5 degrees equals $1.1 \mathrm{~mm}$ on the surface of the globe. Interestingly, Bielschowsky was in the audience 


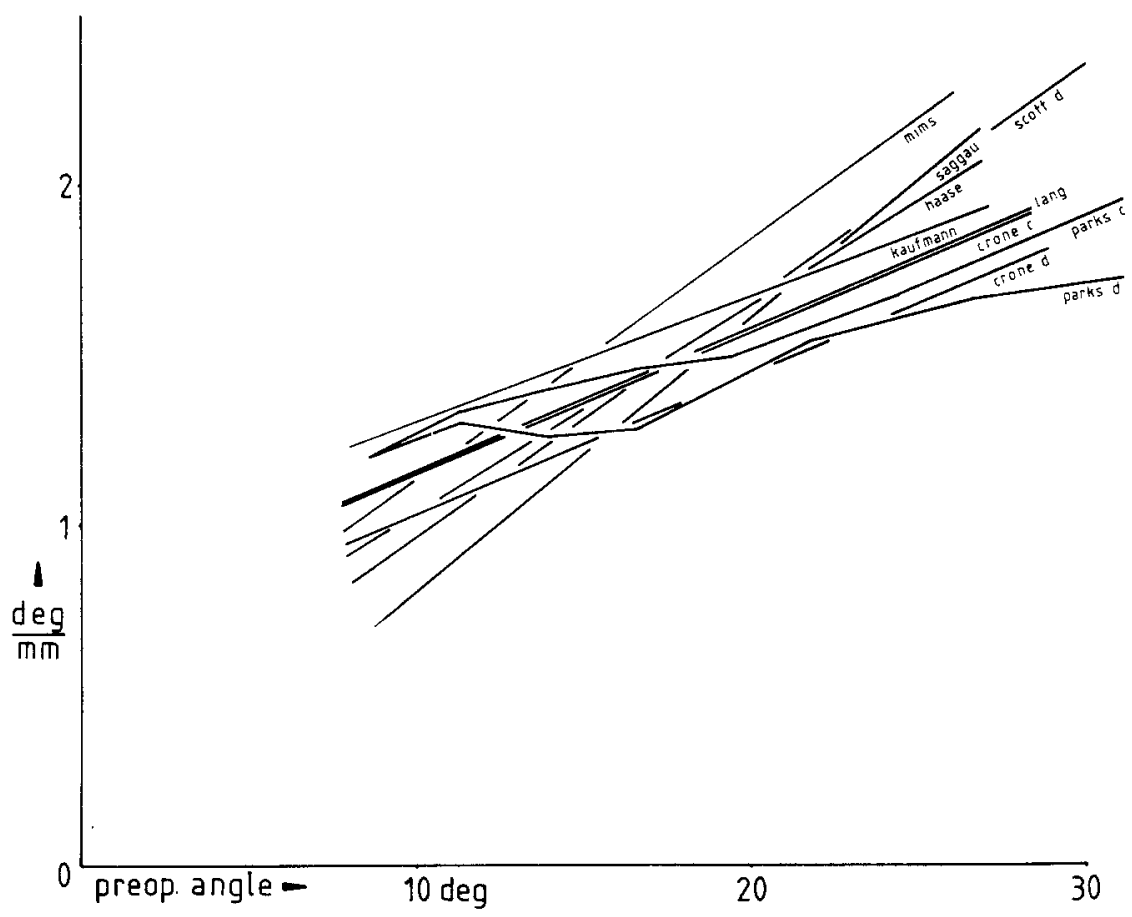

Fig. 1. The relation between effect of surgery (ordinate, degrees of squint - angle change per $\mathrm{mm}$ ), and preoperative squint angle (abscissa, degrees), as found by Scott et al [3], Kaufmann et al [4], Saggau [5], Lang [6], Parks [7, 8], Mims et al [9], and Crone (personal communication). ' $c$ ' or 'd' denotes convergent and divergent squint, respectively. In some cases [3, 4,6 and 9], the regression lines were obtained from the data on the surgical outcome in individual patients as mentioned in tables and diagrams, after conversion of prism diopters to degrees, where necessary. Hence, these data must be interpreted with care. In one case [5], the regression line found by the author was used. Finally, recommendations of Parks $[7,8]$ and Crone are depicted. Note the large spread and the decrease of the degree $/ \mathrm{mm}$ ratio at small angles of squint.

at the time and he expressed his doubts as to whether it was possible to operate with a precision of tenths of a millimeter. Instead, he advocated the use of adjustable sutures. These controversies remain today. Recommendations vary widely (Fig. 1) [3-9]. Some say a recession does more than a resection, while others believe the opposite is true. Finally, most find a lower ratio at smaller preoperative angles of squint. This is a curious finding, because it means that small recess-resect procedures should not result in any significant change of the angle of squint. We have observed on several occasions, however, that for instance a $2 \mathrm{~mm}+3 \mathrm{~mm}$ recess-resect procedure has an effectiveness in the normal range, about 1.7 degree $/ \mathrm{mm}$. We therefore decided to investigate the matter, using our modified version 
of the Robinson computer model of eye movements [10]. We calculated the amounts of surgery needed to reduce a series of squint angles to zero.

In addition, we simulated Faden surgery, addressing in particular the question why Faden surgery not only reduces the squint angle at nearfixation, but also, to a lesser extent, the squint angle at distance-fixation.

\section{Materials and methods}

The Fortran computer model was most generously made available to us by D.A. Robinson (consult [10] for a detailed description of the model). Basically, the Robinson computer model of eye movements employs input data like origins and insertions of the eye muscles, the radius of the globe, the mechanical characteristics of the eye muscles, the anatomical characteristics of the eye muscles, the displacement of the eye muscles in different directions of gaze and the spring constant of the adnexa adjacent to the globe, to calculate the state of contraction of the six eye muscles in any particular direction of gaze. A second part of the model utilizes the states of contraction of the six eye muscles input data to calculate the direction of gaze. Additionally, surgical manipulations, force-duction tests, fibrosis and paresis of eye muscles and other simulated interventions can be used as input data to calculate the change in direction of gaze caused by the intervention. Hence, an angle of squint can, for instance, be entered in the first part of the computer program (in different directions of gaze if necessary) and the effect of surgery can be studied in the second part of the program.

There are several conditions to be met before the model can be employed by a strabologist or an orthoptist. First, the anatomical and physiological input data must be correct and sufficient. Secondly, all pathological muscle changes, surgical interventions and other manipulations must be simulated correctly. All of these conditions were not fully met when Robinson originally presented the model and, unfortunately, this has retarded its introduction. We have concentrated our research in the past years on alleviating the problems that arose where the above conditions were not met.

We applied the following modifications in our model:

Robinson [10] used a hyperbola equation to describe the relation between length and tension in both contracting and non-contracting eye muscles. Instead, we use an exponential equation to describe the mechanical properties of the muscle in the non-contracting state and a series of linear equations to describe the mechanical properties of the muscle in the contracting state.

We have presented evidence previously [11] that the length-tension relation of a non-contracting eye muscle is exponential, like that of skeletal 
muscles and other connective tissues [12-14]. Based on a series of lengthtension measurements of horizontal eye muscle pairs in cases of uncomplicated con- and divergent squint, we found the following equation to describe the relation appropriately:

$$
\text { Tension }(\mathrm{g})=0.7914 \times\left(\mathrm{e}^{0.1526 \times \% \text { Change in Muscle Length }}-1\right)
$$

Muscle-length change is expressed as percentage of primary-position muscle length, assuming a length of the contractile portion of the 4 rectus muscles of $37 \mathrm{~mm}$ [15]. A non-contracting muscle as described by this relation, is slack when shorter than the primary-position length. This is a reasonable assumption, as Asmussen [16] found this to hold true for rabbits (in his experiments, the lateral orbital wall was taken out and the length of the muscle was measured in situ, before taking the muscle out and assessing the length-tension relationship).

The length-tension properties of the innervated, contracting eye muscle are described in our modified model by a series of linear equations with equal constants (i.e. spring constant or stiffness). The spring constant of the lateral rectus in our model is 0.35 gram per degree of eye rotation. Collins et al. [17], and Robinson et al. [18], have demonstrated previously that, at higher levels of innervation, the length-tension relation of an innervated human eye muscle is linear, with equal spring constants for different levels of innervation. In other words, the tension increases proportionately to the length, like in an ordinary spring, and the spring constant remains the same at different levels of contraction.

We found a similar linear relation, with equal spring constants at different levels of contraction, after eye muscle contraction evoked by intravenous administration of succinylcholine chloride, in patients under general anaesthesia during surgery for uncomplicated, horizontal squint [11]. Succinylcholine chloride causes the multiply innervated fibers of the oribital and the global portions of the muscle to contract for several minutes [19-20] due to the activation of acetylcholine receptors that are present, in these fibers, over the entire cell membrane [16]. The singly innervated, orbital fibers also contract, but for a shorter period [16].

In a series of first operations for uncomplicated horizontal squint we found spring constants of approximately 0.35 to $0.50 \mathrm{~g} /$ degree, 2,4 or 6 minutes after the injection of succinylcholine chloride, i.e. at diminishing levels of stimulation. We also found similar spring constants for agonist and ipsilateral antagonist in most cases [11].

The normal range of spring constants of medial and lateral rectus muscles that we found after succinylcholine chloride possibly corresponds with their 
spring constants in the awake state, as can be inferred from earlier measurements of the spring constant in passive, horizontal eye rotation in awake volunteers. The spring constant in passive, horizontal eye rotation is composed of the spring constants of the medial and lateral rectus muscles and the spring constant of the adnexa of the eye. (We found in the model that the horizontal component of the vertical rectus and oblique muscles is negligible.) If the spring constant after succinylcholine chloride and the spring constant in the awake state correspond, then the spring constant in passive, horizontal eye rotation in the awake state should be a bit more than $0.80 \mathrm{~g} /$ degree, i.e. twice the stiffness of a horizontal rectus muscle. Collins et al. [21], indeed found $0.99 \mathrm{~g} /$ degree, on average, for pulling the eye from 30 degrees of adduction to 30 degrees of abduction or vice versa. We found $0.91 \mathrm{~g} /$ degree, on average, for pulling the eye from 5 degrees of adduction into abduction [11]. (In both of these experiments, innervation to the eye muscles was kept constant by letting the patient fixate a target with the other eye.)

It can be argued that the purported correspondence between the spring constant in the awake state is invalid because the exact degree of recruitment of the six kinds of eye muscle fibers during the awake state is unknown, whereas succinylcholine chloride stimulates the multiply innervated fibers preferentially. However, it is likely that the spring constant in the awake state is determined to a large extent by the multiply innervated fibers. The larger part of the singly innervated fibers are of the thick, fatiguable type and are probably used for saccades and excentric gaze. Moreover, Gornig et al. [22], demonstrated that the slow, monophasic action potentials [23] of the orbital multiply innervated fibers are the first to appear in the E.M.G. of the superior rectus and superior oblique muscles of rabbits that, after being tilted to a position that causes the muscles to relax due to the otolith reflex, are subsequently slowly tilted back. Hence, it is likely that the slow, multiply innervated fibers are recruited almost continuously [24], and therefore determine the spring constant of the muscle under static conditions to a large extent.

In the model, $0.35 \mathrm{~g} /$ degree is used as the spring constant for a lateral rectus muscle. A continuous transition from the linear contracting-muscle curve to the exponential non-contracting-muscle curve was obtained by calculating the tension in the muscle according to both equations and then adopting the greater value.

The advantage of using just two simple equations to represent the lengthtension properties of the eye muscles is that parameter values which were only estimates in the original model are now directly derived from measured values. The Robinson model uses an innervation parameter that, in our 
model, is represented by the intersection of a linear length-tension curve with the abscissa of the diagram. In order to estimate the innervational parameter for a lateral rectus muscle when the eye is rotated 30 degrees into the field of action of that muscle, the tension in the antagonist is calculated according to the relaxed-muscle exponential function, and is added to the force due to the adnexa, which is given by 30 times the constant for the adnexa stiffness. The sum of these two forces represents the force that the lateral rectus must overcome to hold the eye in 30 degrees of abduction. The length-tension curve for the associated state of innervation is then completely determined by the tension at 30 degrees of abduction and the slope of the linear length-tension relation. The length-tension relation corresponding to the primary-position state of innervation is given by the tension of the lateral rectus muscle in primary position (approximately 8 grams) and the slope of the linear length-tension relation. The innervation parameter for the lowest possible state of innervation is obtained from the intersection with the abscissa of the linear length-tension curve which is tangent to the exponential function.

The constant for reciprocal innervation can be obtained from the 3 values obtained above using the original formula of Robinson (1975), provided that it is assumed that the innervation for 30 degrees out of the field of action of the muscle is approximately equal to the lowest state of innervation. The disadvantages of not having fully smooth curves are far outweighted by the advantages of having only the following variables: the spring constant of the innervated lateral rectus, the tension in the lateral rectus muscle in primary position, the spring constant of the adnexa and the exponential equation for the non-innervated lateral rectus muscle.

The spring constant of the adnexa of the globe was assumed to be $0.35 \mathrm{~g} /$ degree, compared to $0.48 \mathrm{~g} /$ degree in the original Robinson model. This estimated value gave the best results in simulating passive horizontal and torsional rotation. It is a very difficult value to measure in vivo, because rotating the eye after taking the horizontal rectus muscles off, will confer a small translational movement, that mars the measurement. The spring constant of the adnexa is probably slightly less for torsional eye movements as compared to horizontal and vertical eye movements, as we found only $0.50 \mathrm{~g} /$ degree, on average, in passive, torsional rotation of the eye in awake volunteers [25-26]. (In the latter experiments, we found a linear relation between rotation and torque in all volunteers.)

The lengths of the muscles were taken from the study by Lang et al. [15], (please do not confuse Johan Lang, anatomist, and Joseph Lang, strabologist; both are referred to in this work), $37 \mathrm{~mm}$ for the contractile portion of the rectus muscles; 32 and $29 \mathrm{~mm}$ for the contractile portion of the superior 
and inferior oblique muscles. In the original Robinson model, they were $49.11 \mathrm{~mm}$ (lateral rectus), $38.51 \mathrm{~mm}$ (medial rectus), $41.96 \mathrm{~mm}$ (superior rectus), $42.49 \mathrm{~mm}$ (inferior rectus), $22.28 \mathrm{~mm}$ (superior oblique) and $35.35 \mathrm{~mm}$ (inferior oblique), based on a study by Volkmann [27]. The assumed length of the muscle determines the slope of the length-tension curve because length change in the model is expressed as percentage of the primary-position length. This caused the medial rectus to be much stiffer than the lateral rectus muscle in the original Robinson model. We have found, however, that the spring constants of two muscles of a pair (i.e. ipsilateral antagonist) are, in most cases, similar [11].

The radius of the globe was assumed to be $11.7 \mathrm{~mm}$ conforming to an axial length of $24.6 \mathrm{~mm}$ [15]. It was $12.45 \mathrm{~mm}$ in the original model. In our calculations on Faden surgery, we found individual correction for axial length to be important, as will be discussed.

The Volkmann data [27] on the insertions and origins of the superior and inferior oblique as used in the original Robinson model were altered to the effect that their muscle plane is 51 degrees tilted to the sagittal plane and that the muscle plane of the inferior oblique intersects the center of the globe. The latter assumption minimizes the problem that arises from the large arc of contact of the inferior oblique, i.e. the tendon has a tendency to sideslip too much. Lockwoods ligament is not included in the Robinson model. Guenther et al. [28], have simulated Lockwoods ligament in the model, quite elegantly, but we have the impression that the above measures, i.e. slight alteration of the Volkmann data, suffice. Also, the insertions of the superior and inferior rectus muscles were moved $1 \mathrm{~mm}$ temporally so that the muscle planes approximately intersect the center of the globe. This avoids an adducting action of the vertical recti that was even noticeable in the primary position in the original model.

Sideslip of the muscle tendon in eye movement out of the muscle plane, i.e. horizontal rectus muscles in up or down gaze and vertical rectus muscles in left or right gaze was restricted in the original Robinson model by multiplying the twist of the tendon at the insertion by the cosine of the angle of movement out of the muscle plane [10]. We have found previously, in a CT scan study [26, 29], however, that the muscle does not displace sideways at the level of the posterior pole, restricted by connective tissue sheets that run parallel to the orbital wall. In our model, we have reduced the twist of the tendon at the insertion to zero. However, the muscle follows a straight path from its origin to the point of tangency, like in the original Robinson model. This is not quite realistic, as the muscles are actually following a path that is curved outward [26, 29], but the resulting differences are minor.

The coordinate system of the original model was Cartesian: first the 


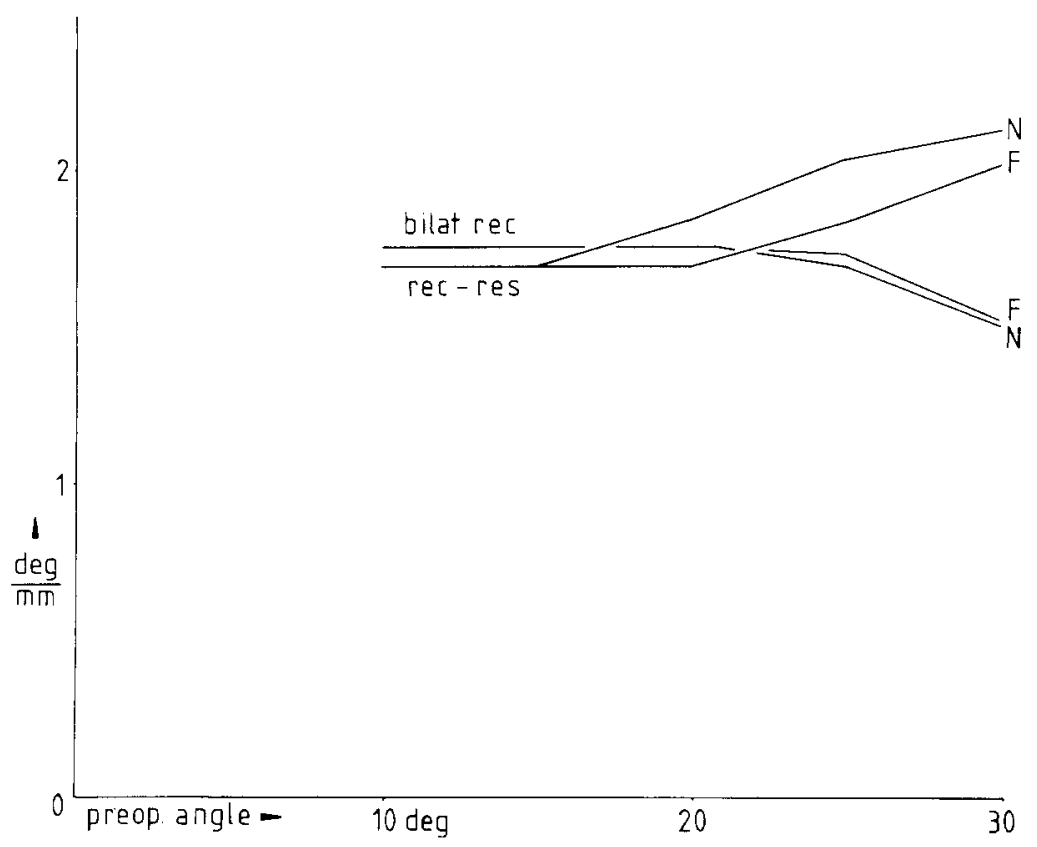

Fig. 2. Prediction by the Robinson computer model of the relation between the effect of surgery and preoperative squint angle, for bilateral recess and recess-resect procedures in convergent squint. The curves marked ' $F$ ' represent the predictions for squint angles measured at distance fixation, the curves marked ' $N$ ' the predictions at near fixation $(30 \mathrm{~cm})$. Note that the degree/mm ratio does not fall off as in Fig. 1, at small angles of squint. At large angles of squint, the model predicts an increase of the ratio for recess-resect procedures only, caused by the least-effect of a very large resection. The decrease of the ratio for bilateral recess procedures at large angles of squint is caused by the slack of the medial rectus muscles after very large recessions.

horizontal angle of a particular gaze position is described, then the vertical angle. This azimuth and latitude system is similar to the one used to designate a place on the earth and, incidentally, similar to the system used in the Major Amblyoscope and Synoptometer. Its great disadvantage is that in tertiary positions a, for instance, 30 degree angle is larger vertically than horizontally. (For comparison: on earth the distance between one of the horizontal circles and the equator is the same everywhere, whereas the distance between the vertical meridians decreases towards the poles.) We have included an algorithm in the model that corrects the vertical angle to the scale of horizontal angle. Hence, the coordinate system consists of horizontal and vertical meridians, or, projected onto a screen, of straight, horizontal and vertical lines (Harms tangents). The use of the Hess screen coordinates (isolatitude horizontally and vertically) [30] is unfounded. It would be best to use the coordinate system described by von Helmholtz [31], 


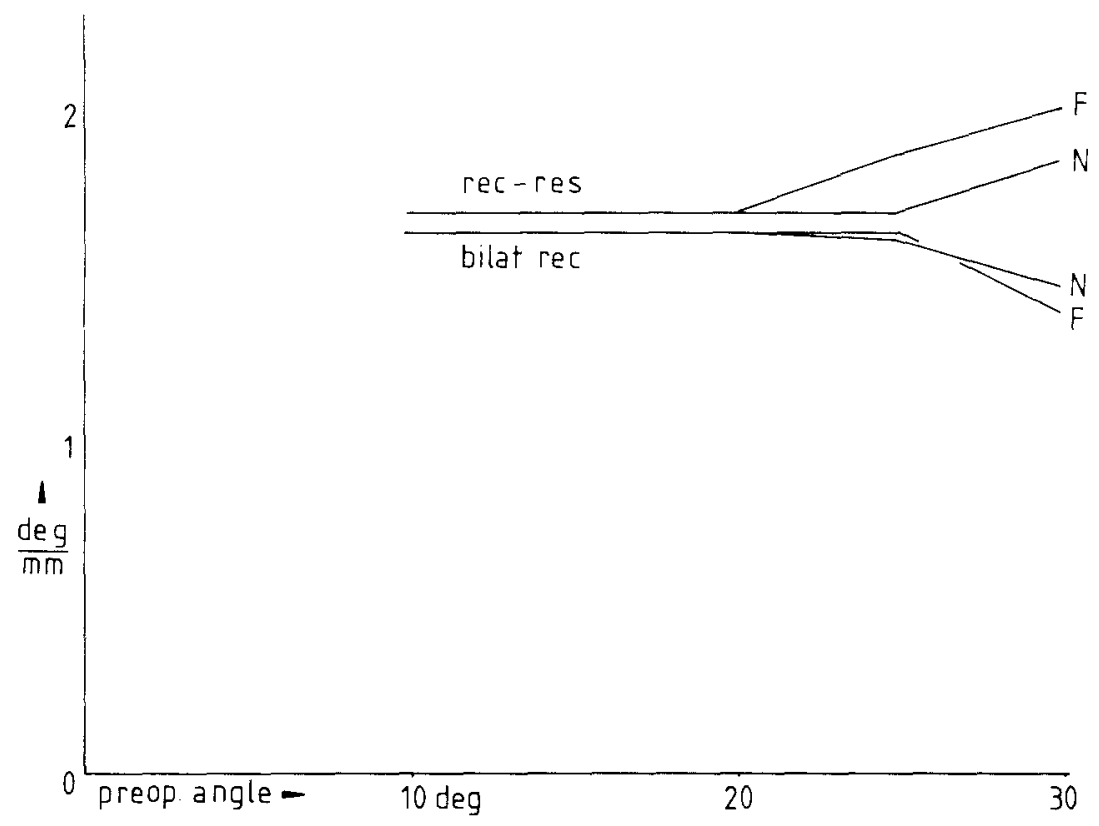

Fig. 3. As Fig. 2, for divergent squint.

(page 41 and pages 67-69; Note: this is not in von Helmholtz' initial papers on eye movements [32]), that, projected on a screen, consists of hyperbolas horizontally and vertically, the curvature of which is approximately half the curvature of the Hess hyperbolas. The great advantage of the system as suggested by von Helmholtz is that all intersections are perceived by the observer as rectangular and that it is free of Listing's pseudotorsion: cyclodeviation can be measured reliably in tertiary positions. The false vertical deviations that accompany large horizontal deviations when measured in tertiary positions using the Major Amblyoscope or Synoptometer are also avoided. Curiously, his system has never been applied for clinical purposes.

In the analysis of the degree $/ \mathrm{mm}$ controversy, we let the model calculate the amount of surgery, needed to reduce an angle of squint, in 5 degree step intervals, to zero. We did that for squint angles at near fixation $(30 \mathrm{~cm})$ and at distance fixation, using bilateral recessions or recess-resect procedures in the model.

In simulating Faden surgery, we let the model calculate the angles that remained after a particular angle of convergence at distance fixation or at near fixation was treated by a $12,13,14$ or $15 \mathrm{~mm}$ Faden on the medial rectus muscles of both eyes. An IBM PC computer was used, fitted with a mathematical co-processor 8087, with an IBM Fortran 77 compiler. 


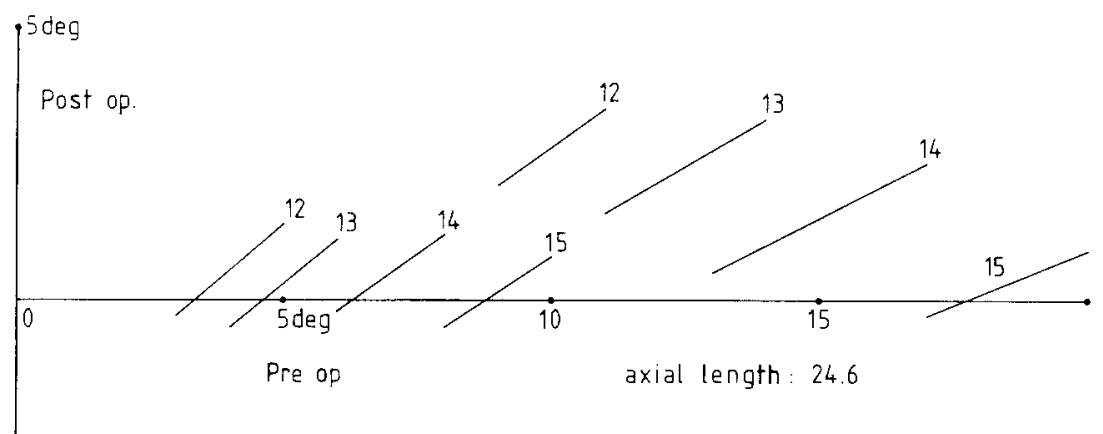

Fig. 4. Prediction by the computer model of the effect of $12,13,14$ and $15 \mathrm{~mm}$ bilateral Faden surgery. The computer calculated the squint angles that remained after performing bilateral Faden surgery on the medial rectus muscles of both eyes (ordinate, degrees). The abscissa represents the preoperative angle of squint (degrees). The results for one particular dosis are connected by lines (these were found to be straight). The left set of four lines ('12', '13', '14' and ' 15 ' denote millimeters between insertion and Faden suture) represent the relation between pre- and postoperative angle at distance fixation. The right set of four lines represent the relation between pre- and postoperative angle at near fixation $(30 \mathrm{~cm})$. The tendency of the slope of the lines (describing the relation between pre- and postoperative angle) to decrease at larger preoperative angles reflects the basic property of Faden surgery to have more effect when the preoperative angle is larger. The axial length of the model eye was $24.6 \mathrm{~mm}$.

\section{Results}

The predictions by our model of the relation between the preoperative angle of squint and the effect of surgery, for bilateral recess and recess-resect procedures in convergent squint are depicted in Fig. 2. The ratios, as found by the computer model, between squint angle reduction and $\mathrm{mm}$ of surgery are represented by the ordinate. The abscissa represents the preoperative angle of squint. The curves marked ' $F$ ' represent the predictions for squint angles measured at distance fixation, the curves marked ' $\mathrm{N}$ ' the predictions at near fixation $(30 \mathrm{~cm})$. Note that the degree $/ \mathrm{mm}$ ratio does not fall off at small angles of squint as in Fig. 1. At large angles of squint, the model predicts an increase of the ratio for recess-resect procedures only, caused by the leash-effect of a very large resection. The decrease of the ratio for bilateral recess procedures at large angles of squint is caused by the slack of the medial rectus muscles after very large recessions. The results found for divergent squint are similar to those found for convergent squint (Fig. 3). The differences between reductions of angles at near fixation and at distance fixation are as expected.

The results of the predictions of the model for Faden surgery are depicted in Fig. 4. Note that, here, the ordinate represents postoperative angle instead 


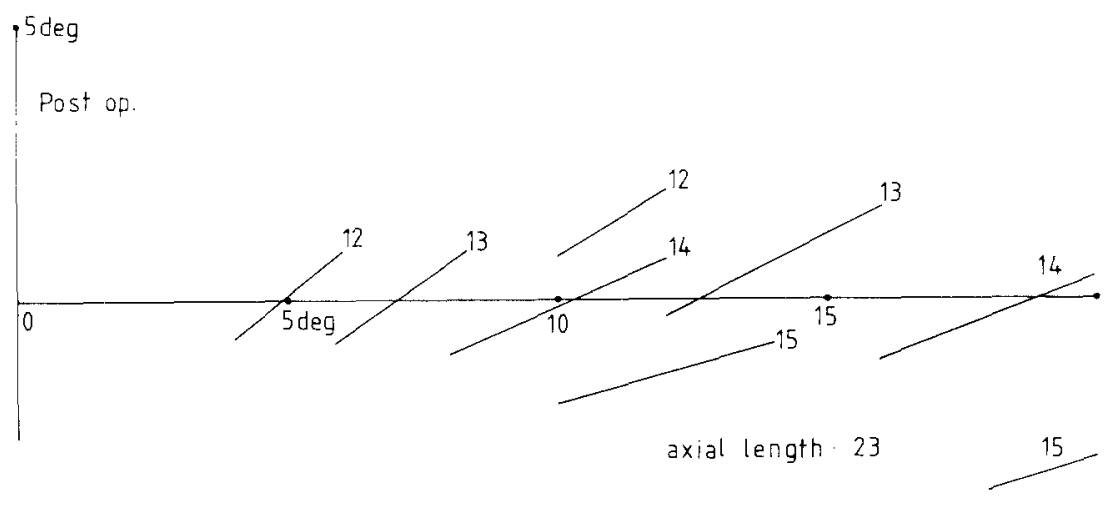

Fig. 5. As Fig. 4, for $23 \mathrm{~mm}$ axial length.

of degree/mm ratio. The various reductions effected by one particular bilateral Faden procedure are connected by lines. The axial length of the eye in our model was fixed initially at an adult value: $24.6 \mathrm{~mm}$, conforming to a radius of $11.7 \mathrm{~mm}$ of the equator of the eye. It is known to influence the result of Faden surgery [30]. We therefore recalculated the effects for an axial length of $23 \mathrm{~mm}$ (Fig. 5), which is a reasonable assumption for average, axial length [31] in the age group that is submitted to Faden surgery. The predictions by the computer model assuming an axial length of $23 \mathrm{~mm}$ correspond closely with clinical experience, as will be discussed.

\section{Comment}

In this study we have demonstrated that the decrease of the degree $/ \mathrm{mm}$ ratio for small angles of squint is not predicted by the model (Figs. 2, 3). On the other hand, the increase of the ratio at large angles of squint is indeed predicted by the model. The difference in degree $/ \mathrm{mm}$ ratio between recessresect versus bilateral recess procedures is also not predicted by our model. Finally, the differences between predictions for angles at near and at distance are as expected. Rather than comparing the predictions of the computer model with those of other authors, we propose to discuss the reasons for the discrepancies instead, as these, to the best of our knowledge, have never been inventorized previously. Four main categories can be distinguished, pertaining to measurement procedures, surgical procedures, sensorics and postoperative muscle physiology.

In recess surgery, the distance between the knots of the sutures and the insertion line may be $1 \mathrm{~mm}$ or more. Measurements are, however, usually taken from the insertion line. This inconsistency introduces an error of 
constant magnitude that predominates at small amounts of surgery and, hence, explains part of the decrease of the degree $/ \mathrm{mm}$ ratio at small angles of squint, as found by most authors.

Most surgeons use 2 sutures per muscle. Therefore, the insertion line that was preoperatively convex towards the cornea, will postoperatively be concave towards the cornea. In fact, the shape of the edge of the muscle between the two sutures is described by a hyperbolic cosine. The average dislocation of the muscle that results from the slack is, due to the nature of a hyperbolic cosine, two thirds of the dislocation of the central part of the muscle. We have measured this distance during surgery and found $1.5 \mathrm{~mm}$ for the central part of the muscle on several occasions, equal to $1 \mathrm{~mm}$ for the muscle on average. It can be argued that the average dislocation is less if a larger part of the muscle is encircled with the suture, but then chances are that the muscle tears in the middle, resulting in even more displacement. The slack enhances a recession but reduces a resection. Hence, the observation that the effect of a recession is larger than that of a resection of similar magnitude may originate from this slack. Much is to be said for using 3 sutures [6].

Incorrect conversion of prism diopters to degrees and incorrect use of prisms results in serious mistakes. The following principles are mandatory [35]: Use hind-surface-frontoparallel calibrated prisms and hold them in that position, convert prism diopters correctly and add or subtract prism diopters using the appropriate formula [35].

The method for determination of the angle of squint may differ among authors. The distance of fixation, the kind of object used for near fixation (does it evoke full accomodation?), patching one eye to find the 'Ruhelage' or the wearing of prisms all influence the angle of squint.

Allocation of patients to different surgical techniques may create a bias in the results. For instance, patients with convergence excess may preferentially be treated by bilateral recess or by Faden surgery.

The axial length of the eye, related to age and refraction, influences the effect of the surgery.

Fibrosis, paresis and cicatrisation after previous surgery all affect outcome. In patients under general anaesthesia for strabismus surgery, we have measured the increase of the spring constant in cases of fibrosis or contracture and found that in most cases the spring constant of the ipsilateral antagonist was increased also [11]. This increase of the spring constant of the muscles is in most cases accompanied by an increase of the spring constant of the adnexa of the globe.

Fusional vergence is a predominant parameter in patients with normal binocular vision. Likewise, an angle of anomalous retinal correspondence 
will be more readily assumed postoperatively. The attitude of the surgeon towards overcorrection complicates this issue even further. Surgeons using a high degree $/ \mathrm{mm}$ ratio will face a lower percentage of overcorrection than would be expected on mechanical grounds, because fusional vergence and anomalous retinal correspondence will correct part of these overcorrections.

Fusional vergence seems to be the main reason for the long persistence of the degree/mm controversy: any dosage formula will, even if it is bad, have a considerable rate of success.

The cause of the squint may persist after surgery. For instance, in heterophoria the normal process of orthophorisation can be perverted by an obligate fixation disparity [36] and, hence, the heterophoria will tend to recur. One may think of persisting mechanical causes as well.

The interval between surgery and assessment of the result determines the effectiveness of other causes, like a persisting cause of the squint, adaptation of the ocular adnexa to the new position of the eye and cicatrisation that may add to this.

After bilateral recess surgery, the four horizontal eye muscles will be slack. The muscle shortens and, hence, the average length of the sarcomeres will be less. Normally, the force that can be generated by the sarcomeres is maximal at slightly more than average muscle length $[14,37]$. It is, at present, unknown whether full rebuilding of the sarcomeres takes place postoperatively, to the effect that the average sarcomere length returns to the preoperative value.

In resect surgery, a part of the tendon is removed that contains muscle spindles. This may influence results. The role of propriocepsis in ocular motility is controversial, however [38].

Summarizing we can say that the discrepancies may be caused by a host of factors, pertaining to measurement, surgery, sensorics and postoperative muscle physiology. It seems mandatory that techniques of measurement and surgery are specified in future publications.

The second part of our investigation concerned Faden surgery, with particular emphasis on the issue of the distance-angle change that results from Faden surgery. Kaufmann [39] found that a 12, 13, 14 and $15 \mathrm{~mm}$ bilateral Faden procedure on the medial rectus muscles reduced the distance angle by a 4 degrees, 6 degrees, 8 degrees and 10 degrees, respectively, and the near angle by 10 degrees, 13 degrees, 16 degrees and 19 degrees, respectively (long term results). The similarity with the predictions of the computer model, with the axial length set at $23 \mathrm{~mm}$, is conspicuous.

Clinical experience shows that Faden surgery, in a patient with no angle of squint at distance-fixation, results in postoperative divergence. At first glance, it seems that sewing the medial rectus muscles to the globe slightly 
behind the equator should not result in any significant change of eye position in such a patient. Several mechanisms have consequently been invoked to explain the distance-angle change after Faden surgery: stretch of the part of the muscle fixed to the globe, connections between muscle and orbital wall, paresis of the muscle due to the Faden surgery, higher spring constant of the muscle because of shortening of the contractile portion and a steeper gradient of retrobulbar pressure in the area medial to the globe. We conclude from the computer model analysis that the effects of Faden surgery can be fully accounted for on mechanical grounds. Superficial analysis apparently underestimates the effect of the displacement of the medial rectus muscle due to Faden surgery. In addition, we confirmed that axial length influences the effect of Faden surgery and that, at large doses, the result of Faden surgery is unpredictable.

\section{Acknowledgements}

We would like to thank D.A. Robinson, D.Eng; for making the computer model available to us, and A.B. Scott, MD; G.K. von Noorden, MD; G. Kommerell, MD, PhD; and D.A. Robinson, D.Eng; for comments. This work was supported by the Alexander von Humboldt Foundation, Bonn.

\section{References}

1. von Graefe A. Beitraege zur Lehre vom Schielen und von den Schiel-Operationen. Graefes Arch Ophthalmol 1857; 3: 177-386.

2. von Pflugk A. Beitrag zur Technik der Schieloperationen. Vornaehung und Zuruecknaehung. Ber DOG 1906: 34-44.

3. Scott AB, Mash AJ, Jampolsky A. Quantitative guidelines for exotropia surgery. Invest Ophthalmol Vis Sci 1975; 14: 428-436.

4. Kaufmann H, Sohlenkamp H, Hartwig R. Ergebnisse der operativen Behandlung bei Strabismus convergens. Klin Mbl Augenheilk 1975; 167: 237-244.

5. Saggau B. Dosierbarkeit und Dosierungsrichtlinien von Schieloperationen in Faellen von Strabismus convergens mit oder ohne Vertikaldifferenz, dissertation, Hamburg, 1976.

6. Lang J. Strabismus-Operationen an den Musculi recti. Klin Mbl Augenheilk 1981; 178: 271-274.

7. Parks MM. Concomitant esodeviations. In: Clinical Ophthalmology. Vol. 1. 12. Philadelphia: Harper \& Row, 1984; 1: Chapter 12: 10.

8. Parks MM. Concomitant exodeviations. In: Clinical Ophthalmology. Vol. 1, 13. Philadelphia: Harper \& Row, 1984; 1, Chapter 12: 9.

9. Mims JL, Treff G, Kincaid M, et al. Quantitative surgical guidelines for bimedial recession for infantile esotropia. Binocular Vision 1985; 1: 7-22.

10. Robinson DA. A quantitative analysis of extraocular muscle cooperation and squint. Invest Ophthalmol Vis Sci 1975: 14: 801-825. 
11. Simonsz HJ, Kolling GH, Kaufmann $\mathrm{H}$, et al. Intraoperative length and tension curves of human eye muscles including stiffness in passive horizontal eye movement in awake volunteers. Arch Ophthalmol 1986; 104: 1495-1500.

12. Fung YCB. Elasticity of soft tissues in simple elongation. Am J Physiol 1967; 213: $1532-44$.

13. Pinto JG, Fung YCB. Mechanical properties of the heart muscle in the passive state. J Biomech 1973; 6: 597-616.

14. McMahon TA. Muscles, reflexes and locomotion. Princeton, NJ, University Press, 1984 : $8-9$.

15. Lang Joh, Horn $T$, von den Eichen U. Ueber die auesseren Augenmuskeln und ihre Ansatzzonen. Gegenbaurs Morphol Jahrb 1980; 126: 817-840.

16. Asmussen G. Morphologische, physiologische und pharmakologische Eigenschaften der auesseren Augenmuskeln und ihre Veraenderungen nach Denervation, dissertation, Leipzig, 1978.

17. Collins CC, Scott AB, O'Meara DM. Elements of the peripheral motor apparatus. Am J Optom 1969; 46: 510-515.

18. Robinson DA, O'Meara DM, Scott AB, et al. Mechanical components of human eye movements. J Appl Physiol 1969; 26: 548-553.

19. Duke-Elder WS, Duke-Elder PM. The contraction of the extrinsic muscles of the eye by choline and nicotine. Proc R Soc B 1930; 107: 332-343.

20. Bach-y-Rita P, Lennerstrand G, Alvarado J, et al. Extraocular muscle fibers: ultrastructural identification of iontophoretically labeled fibers contracting in response to succinylcholine. Invest Ophthalmol Vis Sci 1977; 16: 561-565.

21. Collins CC, Carlson MR, Scott AB, et al. Extraocular muscle forces of normal human subjects. Invest Ophthalmol Vis Sci 1981; 20: 652-664.

22. Gornig H, Asmussen G, Kiessling A.Vorkommen und Bedeutung monophasischer Potentiale im Elektromyogramm der auesseren Augenmuskeln von Kaninche und Katze. Graefes Arch Clin Exp Ophthalmol 1975; 196: 159-167.

23. Kiessling A, Asmussen G, Gornig H. Nichtfortgeleitete Potentiale im Elektromyogramm der Augenmuskeln von Sauegern. Acta Biol Med Germ 1975; 34: 791-803.

24. Robinson DA. The functional behavior of the peripheral oculomotor apparatus: a review. Symp DOG, Freiburg, 1977; 1978: 43-62.

25. Simonsz HJ, Crone RA, de Waal BJ, et al. Measurements of the mechanical stiffness in cyclotorsion of the human eye. Vision Res 1984; 24: 961-968.

26. Simonsz HJ. Investigations of ocular counterrolling and Bielschowsky head - tilt test, stiffness in passive ocular rolling and displacement of recti eye muscles, dissertation, Amsterdam, 1984.

27. Volkmann AW. Ueber die Mechanika der Augenmuskeln. Ber Verh Sachs Wsch 1869; 21: $28-69$.

28. Guenther S, Kusel R, Rassow B. Modellmaessige Beschreibung der Augenmuskelwirkung unter Beruecksichtigung des Ligamentum Lockwood. Fortschr Ophthalmol, in press.

29. Simonsz HJ, Harting F, de Waal BJ, et al. Sideways displacement and curved path of recti eye muscles. Arch Ophthalmol 1985; 103: 124-128.

30. Hess WR. Ein einfaches messendes Verfahren fir Motilit $\{$ tspr $\}$ fung der Augen. Zeitschr f Augenheilk 1916; 35: 201-219.

31. von Helmholtz H. Handbuch der Physiologischen Optik. Vol 3. 3rd ed. Hamburg \& Leipzig: Leopold Voss, 1910.

32. von Helmholtz H. Ueber die normalen Bewegungen des menslichen Auges. Graefes Arch Ophthalmol 1863; 9: 153-214.

33. Roggenkaemper P, Sipp V. Bulbuslaenge und Dosierung der Fadenoperation. Ber Berufsverband der Augenaerzte Deutschlands, Arbeitskreis Schielen 1983; 30-39. 
34. Weiss L. Beitrag zur Anatomie der Orbita. Tuebingen, 1890.

35. Thompson JT, Guyton DL. Ophthalmic Prisms: Measurement errors and how to minimize them. Ophthalmology 1983; 90: 204-210.

36. Crone RA. Orthophorisation. Die binokulare Augenstellung nach Kestenbaumscher Operation. Klin Mbl Augenheilk 1979; 175: 348-352.

37. Gordon AM, Huxley AF, Julian FJ. The variation in isometric tension with sarcomere length in vertebrate muscle fibres. J Physiol 1966; 184: 170-192.

38. Kommerell G. Bericht ueber den 'International Workshop on Proprioception of the Ocular Muscles', Matsuyama, Juni 1986. First Symposium of the Bielschowsky-Gesellschaft fuer Schielforschung, Goettingen, October 4-5th, 1986.

39. Kaufmann $\mathrm{H}$. Wirkungsprinzipien und Resultate verschiedener Operationsmethoden bei Strabismus horizontalis. Ber Berufsverband der Augenaerzte Deutschlands, Arbeitskreis Schielen 1983; 30-39.

Address for correspondence: Dr. H.J. Simonsz, Netherlands Ophthalmic Research Institute, P.O. Box 12141, 1100 AC Amsterdam, the Netherlands 